\title{
The understanding and experience of students, tutors and educators regarding reflection in medical education: a qualitative study
}

\author{
Fiona Muir \\ Undergraduate Community Medical Education, University of Dundee, UK \\ Correspondence: Fiona Muir, Undergraduate Community Medical Education, Clinical and Population Sciences and Education \\ Division, University of Dundee, UK, Email: f.e.muir@cpse.dundee.ac.uk
}

\begin{abstract}
Objectives: This exploratory study was designed to investigate the understanding and experience of students, tutors and medical educators with respect to reflection in medical education during the $\mathrm{MBChB}$ medical degree programme.

Methods: A qualitative approach was employed using semistructure interviews. Seven medical students, eleven tutors and eight medical educators participated in the study. An inductive thematic analysis was used to accomplish the aim of this study.

Results: The results indicate that students, tutors and educators have an incomplete understanding of reflection. The cause exists at several points, not only at curriculum level but also at the level of the educator, tutor and the student. Whilst the study presents information regarding
\end{abstract}

curriculum deficits and individual needs it also signifies that policy documents are not clearly understood. Assumptions were made by participants regarding the teaching, learning and assessment of reflection indicating a need for a review of student and tutor preparation.

Conclusions: The importance of reflection is frequently noted in the literature as an essential characteristic for professional competence. This research has highlighted the need for a much greater emphasis on reflection in or through teaching, learning and assessment. Suggestions to overcome these are offered.

Keywords: Health professional education, reflection, undergraduate medical education

\section{Introduction}

Modern day changes in medical education have identified standards which students must achieve before they become qualified practitioners. The General Medical Council policy documents ${ }^{1,2}$ highlight the need for the professional to be reflective. These standards are significant as they clearly define the qualities and abilities essential for a competent and reflective doctor and for the continuing professional development of medical graduates.

\section{Defining reflection}

Key definitions of reflection and critical reflection derive from the early work of educationalists such as Dewey ${ }^{3}$ and Schön. ${ }^{4}$ In the last two decades of the twentieth century these two terms have increasingly appeared in the educational literature to support practice and practice development, education and research. Many writers ${ }^{5-11}$ have contributed definitions of reflection and critical reflection. Reflection is described using numerous terms: memory, thinking, thought, indication, mirror image. Although wide ranging and difficult to define completely, Hancock ${ }^{12}$ reviews the number of definitions that exist and concludes the following common characteristics:

\footnotetext{
“...is based in practice; is capable of developing new knowledge; is consciousness raising; helps turn experience into learning; raises self awareness; develops intellectual skills; liberates individuals from conventional, traditional ways of thinking; is creative; can be both an adult and experiential learning technique."
}

Boyd and Fales ${ }^{13}$ advocate the use of critical reflection differentiates between those who merely become proficient in their learning and teaching and those who are also 
cognitively or affectively changed by the experience. In the medical context it is conceived as the ability of doctors to reflect critically about their own reasoning and decisions, inquiry and translation skills. ${ }^{14,15}$

Critical reflection is:

\begin{abstract}
" $a$ window through which the practitioner can view and focus the self within the context of his/her own level of experience in ways that enable him/her to confront, understand and work towards resolving the contradictions within his/her practice between what is desirable and actual practice." 16
\end{abstract}

This study is different in character from other studies on reflection reported in nurse, teacher, general education and medical publications. Several writers have described interventions using reflective learning techniques and strategies to develop the student's reflective skills and abilities to evaluate new and existing programmes. ${ }^{17-20}$ Much of the literature suggests that there is an assumption that tutors know how to reflect and can teach reflection. It is also assumed that students, on completion of their course, are able to reflect critically on practice. ${ }^{21-23}$ As a consequence of reflecting they contribute to their own personal and professional development. However, students routinely acquire knowledge without having the ability to use it in a meaningful context. Thus, there is a need for participation in authentic activity and to observe practitioners 'wrestling with problems of the world. ${ }^{24}$ The learner becomes involved in the community of practitioners and increasingly assumes the role and identity of full participants. Accepting this without examination presumes that tutors and students understand, and can apply the skills of reflection to their development needs and their teaching.

\section{Methods}

\section{Aim}

Whilst previous research has looked more widely at interventions using reflective learning techniques and strategies to develop the student's reflective skills and abilities to evaluate new and existing programmes, there appears to be limited research pertaining to the understanding and experience of reflection in the medical undergraduate degree programme. The aim of the present study was to:

- Establish what the student, tutor and educator understand by the terms 'reflection', 'critical reflection' and 'reflective practice'?

- Describe the students', tutors' and educators' experiences of 'reflection' in terms of teaching, learning and assessment?

- Explore what support is offered by the Medical School to develop the students' and tutors' skill of 'reflection'?

- Identify what, if anything, the student, tutor and educator would like to see change in how this support is effected?

\section{Design}

An exploratory case study ${ }^{25}$ approach was adopted to reflect the interactive nature of the experiences of students, tutors and educators in one educational setting. Semistructured interviews were carried out with students, tutors and educators involved in the undergraduate medical degree programme within one university in the UK.

\section{Participants}

The Medical School delivers a five year integrated, systems degree programme in which contributions come from anatomy, biochemistry, physiology, pharmacology, behavioural science and public health. The undergraduate programme recruits approximately one hundred and sixty students each year and the education is delivered by a range of professionals within the five components of the course. These five components are systems based teaching, ward based teaching, clinical and communication skills, integrated teaching area and the community.

The participants in this study were staff and students associated with years one-three of the medical undergraduate programme. The total number of participants was twenty six, male (thirteen) and female (thirteen). The staff included tutors who were general practitioner and nonmedical staff responsible for the curriculum delivery within the community part of the programme; faculty educators who were University (medically) educated and responsible for the development and delivery of the medical degree programme; students in years one-three of the programme. The non-general practitioner staff included nurses, retired teachers, counsellors and others.

All participants were eighteen years of age or older and their medical education experience ranged from one to twenty years. All teachers, both tutors and educators were directly involved in teaching, curriculum design, planning and/or development. Participants were recruited through the curriculum group responsible for curriculum development, student year lists and community based tutors. Data was derived from the one case and not selected on a random basis. Kvale ${ }^{26}$ suggests that one conducts interviews with as many people as necessary in order to gain the information sought. The reason for choosing these individuals was that they were easily accessible and known to the author. The author is directly involved in the teaching of students and for supporting the tutors within the community part of the programme and regularly attends the meetings where much of the programme development and delivery is discussed.

\section{Procedure}

Ethical approval at the university level and local research ethics committee was obtained before the research began. Ethical considerations as defined in the British Educational Research Association Guidelines ${ }^{27}$ applied throughout the research. Anonymity and confidentiality assurances were given so that the rights of the individuals were not com- 
promised. Participants were given an introductory letter via email with the details of the study, why the study was being carried out and the format of the interview. They were given the opportunity to decline participation in the study before arranging a meeting for interview. Queries were answered verbally and written consent was obtained. This provided a degree of proof that the person was aware of the nature of the study and they had informed consent to take part. A pilot study was conducted with two members of staff who would not be participating in the main study. An interview guide was used to provide a framework for the interview. Participants were given a brief introduction to the purpose of the study and an explanation of what they were being asked to do. Each participant was interviewed in a place convenient to them and for as long as required. This took on average approximately forty minutes, with the interviews spread across six months during 2007. The same semi-structured interview guide was used for all participant groups. However, as the questions were not completely pre-determined, there was an opportunity to change the words but not the meaning of questions to help the participant understand them. Clarification and probing for further responses enabled the participants to understand the questions better and this, Parahoo ${ }^{28}$ claims, enhances validity.

\section{Analysis}

Interviews were recorded, transcribed verbatim then listened to again along with the transcriptions for accuracy and anonymity. As outlined by Miles and Huberman ${ }^{29}$ the data was then analysed using an analytical process which involves a number of interconnected stages to classify and organise data according to key themes, concepts and emergent categories. Internal validity ${ }^{30}$ was assessed in various ways including reflexivity, triangulation, peer judgment and validation of the data with the interviewees.

Reflexivity is the continuous process of reflection by the researcher on anything in the research environment: his own values, preconceptions, behaviour or presence and those of the participants, which may affect responses. Therefore the author considered the rapport with the interviewee, the way in which the participant was prompted and probed during questioning and the sequence of the questions. The author reappraised coding of the responses, interpreting the recording of the data/transcripts and the handling of difficult interviews.

The author was aware that her presence could have affected the situation as participants might have wished to impress, avoid or influence her as the researcher, particularly as she is a member of the teaching staff within the University. However, this effect was reduced by ensuring as much as possible a careful presentation of the self.

Member checking is a process through which respondents verify data and the interpretations thereof. ${ }^{29}$ Participants were asked at interview if they would read and validate their transcript. Some participants declined providing reasons such as they would not have time to look over the transcript or they did not want to read what they had said at interview. The author returned to five of the interviewees with a copy of the interview transcript to review, clarify, and confirm accuracy of the transcript detail. An alternative way to validate the data is to ask other researchers to examine all or part of the transcripts. Thus, a peer validated part of the data.

\section{Results}

Due to the number of responses the results from the three participant groups, students', tutors' and educators' understanding and experience of reflection, have been combined. The main themes identified in the analysis are as follows: understanding reflection, understanding reflection, standardising the approach to reflection, the reflective process, time to reflect, patient care, teaching, learning and assessment, the facilitator's attributes and knowledge of the General Medical Council requirements. ${ }^{1}$

\section{Understanding reflection}

Participant groups appeared to have some similar, and some differing views in their understanding of 'reflection', 'reflective practice' and 'critical reflection' (Box 1). Educators expected students to become, and assumed that they would become, self-developed reflectors. Tutors and students required clarification of the meaning of each term and also of the expectation held by the Medical School regarding the students' ability to become reflective.

\section{Box 1: Understanding reflection}

\section{Student}

"Well it's the first I've heard of it to be honest. I'm not really sure... I guess it's like to explain something. No, I haven't come across them before. We definitely haven't been told reflective practice" (Student one)

\section{Tutor}

"Critical reflection, anything that reflects almost anything we do in this life, whether it's working situation, personal situation. To reflect on how things are going, what our practice is like, what underpins them I suppose" (Tutor one)

\section{Educator}

"I guess critical reflection could/would apply to anything you do in everyday life...Reflective practice, I

guess...reflecting on your clinical practice...how you would do something differently in the future so it's learning from experiences to develop yourself" (Educator four)

Standardise the approach to reflection

All participant groups indicated a need for more reflective education in the early years of medical education. The three participant groups indicated that reflection should be introduced early in the programme of study and revisited throughout the curriculum (Box 2). Students also identified a need to know the Medical School's expected standard 
and criteria for reflection. In particular, they wanted to know the course requirements for demonstrating a depth of their understanding and a critical awareness of their learning.

\section{Box 2: Standardise the approach to reflection: Teaching} early in the curriculum

\section{Student}

"I think it is quite useful to get it right, right from the start rather than getting use to the wrong thing then it would be sort of difficult to change your habit then. I think it would be better to introduce it in first year" (Student one)

\section{Tutor}

"From day one.... it's really important right from the start. It's really important that they are thinking about the implications and the effect they might have on that person. I do think they have to have some sort of introduction just to try and explain what we mean by reflective thinking and reflective practice. I think it always has to be revisited because we all fall into a pattern of thinking that we are doing it and not necessarily doing it and I don't just mean the students, I think we are all guilty of that" (Tutor six)

\section{Educator}

"I assumed they get some sort of instruction but I have to be honest I don't know what that is....As early as possible because what you want is to make it second nature for students to be able to do that throughout their work...my gut feeling is first year" (Educator eight)

\section{The reflective process}

Few teaching staff used reflective strategies such as models or frameworks to guide the student through a process of reflecting. Students did not know of such a process, nor did they know what the Medical School expected of them. This data suggest that there is a need for a standardised approach to the teaching of reflection. Participants with experience in healthcare other than medicine, in particular nursing, had greater experience of using a reflective framework.

\section{Box 3: Time for reflecting}

\section{Student}

"...we have to make time for it because we have to do it" (Student four)

\section{Tutor}

"...one of the students pointed out that they did not have a lot of formal training [for reflecting]...they hadn't had enough formal training and that was an omission and...it is really something that we should spend more time with" (Tutor seven)

\section{Educator}

"I don't think it would have to be a huge amount of time, but you know some sort of time set aside to go through examples. That would be a useful thing to get them to go away and do a reflective piece of work to get them to try it out, you know and then have someone say to them, yes that's what we mean or you've missed the point completely, and be able to support them in that way" (Educator eight)
The majority of participants recognised the value of reflection as an educational tool.

\section{Time to reflect}

Time to reflect was an area of concern. It was viewed as necessary and important, particularly for the more complex issues of practice, the completion of the assessment and for continuing education (Box 3 ).

\section{Patient care}

Participants related the importance of reflection to 'best' patient care, how the care provided by healthcare professionals affects the person, how the patient feels and in the event of a significant event with a patient how practice can be changed for the future (Box 4).

\section{Box 4: Significance for patient care}

\section{Student}

"I think it is one of the essential things for today's doctors to be able to look back on what you do...at the end of the day it's that you improve for patient care" (Student two)

\section{Tutor}

"I think it's important to everybody who is dealing with a client base...it's all very well knowing how to do a procedure but if you don't know how it affects the person ...how they are feeling about it you can never change your practice..." (Tutor six)

\section{Educator}

"If you're writing a case discussion based on a particular patient...you have to be a good reflector...because you are thinking was there a way that particular case was handled and how did that correlate with what I've read...what things went well and what things went badly..." (Educator six)

Teaching, learning and assessment

Student and tutor training and preparation were regarded as necessary to assist the student in meeting their course requirements. With an emphasis on educational theory, education and training are required to support practice. There is a need for the tutor to have knowledge and experience to encourage and assess the student's reflective ability. Preparation for teaching was varied; only one tutor had a formally recorded teaching certificate, whilst the others had no formal training.

Within this medical school students' approaches to reflection on both 'thinking' and 'doing' are assessed, throughout the programme of study, in the context of a portfolio by using written evidence from their clinical practice. The portfolio recognises the centrality of reflection as a learning process as laid out by the Royal College of General Practitioners. The evidence in the portfolio is a 'test of reflective ability'. All participant groups considered the portfolio assessment to be a significant and important part of the programme. However, students and tutors received little or no guidance and educators assumed that students knew how to complete the assessment. Partici- 
pants indicated that resources need to be developed to support both learning and teaching. These were seen as essential for the completion of the portfolio assessment.

\section{The facilitators' attributes}

The facilitators' attributes and the importance of sharing experiences from practice to support the development of the student's reflective skill were deemed necessary (Box 5).

\section{Box 5: The facilitators' attributes}

\section{Student}

"Firstly to seem interested in what we're doing...wishing you to achieve a certain standard...enthusiasm, a good knowledge of what we're being ask to do...being well informed" (Student three)

\section{Tutor}

"Somebody who can reflect on what they do themselves so you have to have somebody who knows what it means but not just in theory but who can actually do it for their own self because we can't encourage the students to do it if we're not doing it or understand why we're doing it. I think you have to have a really good rapport with the students and an ability to pick on certain things that are said and not pass them by tutor six" (Tutor six)

\section{Educator}

"...encourage and give examples...someone who you know uses reflective practice"(Educator three)

Knowledge of the General Medical Council requirements The majority of participants were aware of the significance of reflection for medicine, in particular, the association with the General Medical Council requirements and its relevance to the course requirements. However, there was a general lack of awareness and understanding of the actual General Medical Council requirements.

\section{Discussion}

Comparison with existing literature from health and teaching professions indicates that many of the terms 'reflection' are comparable to those identified within the literature, whereby they have been used loosely and interchangeably, and numerous definitions and common characteristics exist. ${ }^{12,33}$ Unlike other studies this case study findings shed light on 'reflection' in medical education. Although there was some variation participants' had, in general, a similar understanding and experience of reflection, namely the application of reflection to practice and for future practice; the application to life and relating to the self; and the application to education. Although there was uncertainty about the meaning of the term 'reflection' and a need for clarity in their understanding most participants' knew of the significance of reflection. There was a concern that the term may be misused because of the different ways in which it is interpreted. Thus, an understanding of the terminology may enable the student and the teacher of medicine to engage in broader cognitive processes. As evidenced in this case study if people do not understand the terms, then a starting point would be in providing the definitions recommended, scrutiny of the technique, for example, from participating in a demonstration facilitated by expert educators and offering support in the process of reflective learning. The learning indicated by individuals through informal 'ad hoc' activities had no strategically devised framework. They were given little or no preparation to reflect from the Medical School. Students accepted that there was an expectation from the Medical School that they could and would reflect as part of their course. This expectation did not lead to formalised learning because there was no formal 'modus operandi', in that the reflective learning was not organised or structured.

Within this study participants acknowledged the importance of reflection to their profession and defined their learning needs but the process for reflecting as part of the programme assessment was not transparent. Few participants related to a process for reflection or knew of any reflective strategies which can be used to structure the reflective process and develop the student's knowledge and skill of reflecting.

Students of medicine are required to be self directed learners, demonstrate better thinking skills, critically appraise evidence ${ }^{1}$ which is informed by 'modern educational theory'. ${ }^{31-32}$ Of particular significance was the identification that participants had received minimal or no formal training or education in reflection and few resources are provided by the Medical School. There was an assumption that students and tutors understand the concept of reflection. The comments made by the majority of participants illuminate the need for resources such as a handbook, educational techniques such as a reflective model or a framework, course document, information pack and guidance.

As the employer, the University/Medical School has an obligation to provide staff with the required knowledge and skill for teaching. Thus, staff training and continuing professional development are viewed as essential.

The role of reflection in the ongoing professional development of staff to support student learning, in this case study was not transparent. Thus, it would seem that there is an opportunity for staff education, for example by focussing on the development needs of the student and tutor namely, reflective skill expertise. All participant groups suggested that in order to support the students' learning the facilitator must use a standardised approach to their teaching. Thus, clarifying the facilitators' role could assist in determining what knowledge needs to be accessed and organised for teaching at different stages in the students learning. Educators indicated that the revalidation process, by which licensed doctors across the UK demonstrate to the GMC on a regular basis that they remain up to date and fit to practise, is also associated with patient safety. ${ }^{2}$ Thus, with such significance in the context of medical education 
students could be clearly informed of the benefits of reflection and the need to be critically reflective as part of ongoing professional development, lifelong learning, and for safe patient care. While educators in this study assumed that students would know how to 'critically analyse' students did not know how they were being assessed or know of an assessment criteria. There is a lack of any reflective guideline or assessment criteria pertaining to the different levels which would guide the student within years one-three of the curriculum. This perhaps explains why students are confused by 'reflection', participants do not know of the specific criteria requirements for assessment and they view the assessment as a 'tick the box' exercise.

Training in the use of portfolios for learners, their mentors and assessors was seen to be needed. This is consistent with studies in portfolio preparation for postgraduate medical education. ${ }^{34-35}$

All participant groups in this study indicated that they need time to reflect and this is as an area of concern. If the Medical School accepts the view that there is no time to reflect then they run the risk that students and teachers will have very little awareness of the potential which reflection has to offer for enhancing professional development. They may not be able to present a coherent understanding of the concept or apply it in any meaningful way to practice.

Students in this study receive little or no guidance while tutors and educators assume that students know how to complete the assessment. Participants gave a clear view of the need for developing the student's reflective skill within the early part of the programme and the need to revisit reflection throughout the programme of study. This endorses the view of Burrows ${ }^{36}$ (nursing) and Kidd and Nestle ${ }^{37}$ (medicine) who suggests that there is a need for reflection to be incorporated early in the medical programme and to value reflective practice as a core professional skill.

Tutors had either little or no knowledge of the programme requirements; did not perceive reflection as a part of their teaching remit; associate reflection with part of their role as a teacher, or know of the overall course outcomes. Therefore, it will be important to consider the preparation and support which is offered to facilitators to develop their knowledge. Despite the relevance and importance of the General Medical Council policy documents, $1,2,38$ some participants in this study lacked an awareness of the policy and the course requirements. Others recognised an association between reflection and the General Medical Council requirements, and the significance of reflection to medicine.

Given the significance of the policy documents it would seem that education providers can play a leading role in implementing policies for lifelong learning. ${ }^{39}$ They could make clear how reflection fits in with these documents particularly when it is a requirement of the undergraduate medical programme, recognised as a lifelong learning tool and a requirement for appraisal and revalidation. ${ }^{40}$

This study has encouraged tutors to consider the theoretical knowledge which is required to support their practice. The challenge for educationalists will be to develop an expert understanding of the learning characteristics and learning styles of their students, and to accumulate a repertoire of strategies that they can implement with different people.

Compared with previous work, this methodological approach added value in that, it facilitated a rich exploration of students', tutors' and educators' understanding and experience of reflection in the 'here' and 'now.' The qualitative research described has identified relevant issues and concepts in terms of what curriculum development is required to illuminate an area of practice which holds such importance.

\section{Limitations of the study}

The limitations of the present study include the small sample size of students, tutors and educators in exploring the understanding and experiences of reflection within one organisation. The study was intended to explore and gain an understanding of the case in its complexity and its entirety, as well as its context, and provide a rich description so that readers can see whether the study is applicable to their situation, or not. It may in turn become a tentative hypothesis for further research. ${ }^{41}$

\section{Future Considerations}

The next step is to develop the support and advice available to students and staff informed by learning resources. The support and information within the course resources should be of a set standard with protected time for reflection; develop continuing professional developments courses and to ensure students and tutors have explicit assessment criteria.

Future research also needs to investigate whether medical educationalists in the context of reflective education have academic knowledge which is relevant, and to examine how the facilitator of medicine reflects as a lifelong learning tool as part of their ongoing professional development, and for the appraisal and revalidation process.

\section{Acknowledgements}

This research was carried out in part fulfilment for the Degree of Doctor of Education. A special thanks to all the participants within the study who gave me the opportunity of capturing their thoughts and experiences. Ethical approval was obtained from the University of Dundee and University of Strathclyde.

\section{References}

1. General Medical Council. Tomorrow's Doctors: Recommendations on Undergraduate Medical Education. $2^{\text {nd }}$ ed. London: General Medical Council; 2009. 
2. General Medical Council. Good doctors, safer patients. 2006 [cited 2009 March 03]. Available from: http:// www.gmc uk.org/about/reform/Revalidation.asp

3. Dewey J. How we think. Boston: Health; 1933.

4. Schön DA. The reflective practitioner. How practitioners think in action. New York: Basic Books; 1983.

5. Boyd EM, Fales AW. Reflective learning: key to learning from experience. J Humanist Psychol. 1983;23:99-117.

6. Boud D, Keogh R, Walker,D. Reflection: turning experience into learning. $2^{\text {nd }}$ ed. London: Kogan Page; 2000.

7. Jarvis P, Holford J, Griffin C. The theory and practice of learning. London: Kogan Page; 1998.

8. Reed J, Proctor S. Nurse education: A reflective approach. London: Edward Arnold; 1993.

9. Reid B. 'But we're doing it already!' Exploring a response to the concept of reflective practice in order to improve its facilitation. Nurse Educ Today. 1993;13:305309.

10. Glen S, Clarke A, Nichol M. Reflecting on reflection: A personal encounter. Nurse Educ Today. 1995;15:61-68.

11. Wong F, Kember D, Yan L. Assessing the levels of student reflection from reflective journals. J Adv Nurs. 1995;22:48-57.

12. Hancock P. Reflective practice-using a learning journal. Nurs Stand. 1998;13:37-40.

13. Boyd EM, Fales A.W. 'Reflective learning: key to learning from experience'. J Humanist Psychol. 1983;23:99117.

14. Mamede S, Schmidt $H$. The structure of reflective practice in medicine. Med Educ. 2004; 38:1302-1308.

15. Lipman M. Critical thinking: What can it be? Institute for Critical Thinking Resource Publication. Series 1. No. 1. New Jersey: Montclair College, Upper Montclair; 1988.

16. Johns C. Reflective practice: Revealing the (he) art of caring. Int J Nurs Pract. 2000;7: 237-24.

17. Arseneau R. Exit rounds: a reflection exercise. Acad Med. 1995;70:684-687.

18. Snadden D, Thomas ML, Griffin EM, Hudson H. Portfolio based learning and general practice vocational training. Med Educ. 1996;30:148-152.

19. Ker J. Developing professional clinical skills for practice-the results of a feasibility study using a reflective approach to intimate examination. Med Educ. 2003;371:3441.

20. Boenink AD, Oderwald P, de Jonge W, van Tilburg W. Assessing student reflection in medical practice. The development of an observer-rated instrument: reliability, validity and initial experience. Med Educ. 2004;38:368-377. 21. Hatton N, Smith D. Reflection in teacher education: toward definition and implementation. Teaching and
Teacher Education. 1995;11:33-49.

22. Kuit J, Reay G, Freeman R. Experiences of reflective teaching. The institute for learning and teaching in higher education. London: Sage Publication; 2001.

23. Mamede S, Schmidt, H. Correlates of reflective practice in medicine. Adv Health Sci Educ Theory Pract. 2005;10:327-337.

24.Patel VL, Glaser R, Arocha JF. Cognition and expertise: acquisition of medical competence. Clin Invest Med. 2000;23:256-260.

25. Yin R. Applications of case study research. London: Sage; 1993.

26. Kvale S. Interviews. London: Sage Publication; 1996.

27. British Educational Research Association Revised Ethical Guidelines for Research. 2006 [cited 2006 May 04]. Available from: http:www.bera.ac.uk/publications/guides.p hp

28. Parahoo K. Nursing research: principles, process and issues. Great Britain: Palgrave; 1997.

29. Miles M, Huberman, MA. Qualitative data analysis. $2^{\text {nd }}$ ed. California: Sage Publications; 1994.

30. Lincoln YS, Guba EG. Naturalistic inquiry. Newbury Park California: Sage; 1985.

31. Brookfield SD. Developing critical thinkers. San Fransisco: Jossey Bass; 1987.

32. Knowles Z, Tyler G, Gilbourne D, Eubank M. Reflecting on reflection: exploring the practice of sports coaching graduates. Reflective Practice. 2006;7:163-179.

33. Teekman B. Exploring reflective thinking in nursing practice. J Adv Nurs. 2000;31(5): 1125-1135.

34. Challis M. Portfolio-based learning and assessment in medical education. Med Teach. 1999;21:370-386.

35. Pearson DJ, Heywood P. Portfolio use in general practice vocational training: A survey of GP registrars. Med Educ. 2004;38:87-95.

36. Burrows DE. The nurse teacher's role in the promotion of reflective practice. Nurse Educ Today. 1995;15:346-350.

37. Kidd J, Nestle D. Facilitating reflection in an undergraduate medical curriculum. Med Teach. 2004;26(5):481486.

38. General Medical Council. Revalidation for doctorsensuring standards, securing the future. London: GMC; 2000.

39. Department of Health. The NHS Plan- a progress report. London: HMSO; 2003.

40. General Medical Council. Revalidation for doctors. Ensuring standards, securing the future. London: General Medical Council; 2000.

41. Burns R. Introduction to research methods. $4^{\text {th }}$ ed. London: Sage; 2000. 